\title{
Successful cognitive aging in persons living with HIV infection
}

\author{
Lauren Malaspina $\cdot$ Steven Paul Woods • \\ David J. Moore • Colin Depp • Scott L. Letendre • \\ Dilip Jeste • Igor Grant • \\ The HIV Neurobehavioral Research Programs (HNRP) \\ Group
}

Received: 4 October 2010 /Revised: 27 October 2010 /Accepted: 8 November 2010/Published online: 30 November 2010

(C) The Author(s) 2010. This article is published with open access at Springerlink.com

\begin{abstract}
The number of older adults living with human immunodeficiency virus (HIV) infection is growing and this subpopulation of the epidemic is at heightened risk for a variety of poor health outcomes including HIV-associated neurocognitive disorders. The current study sought to examine the factors associated with freedom from neurocognitive impairment in older HIV-infected adults. Participants included 74 middle-aged and older (mean age 51 years), HIV-infected individuals with a mean estimated duration of infection of 17 years who underwent comprehensive neuropsychological, psychiatric, and medical evaluations. Successful cognitive aging (SCA) was operationally defined as the absence of neurocognitive deficits as determined by a battery of wellvalidated cognitive tests and self-endorsed cognitive complaints. Thirty-two percent of the cohort met these criteria. Compared to the group that did not meet these criteria, successful cognitive agers had significantly lower lifetime
\end{abstract}

L. Malaspina

Albert Einstein College of Medicine,

Bronx, NY, USA

S. P. Woods $(\bowtie) \cdot$ D. J. Moore $\cdot$ C. Depp $\cdot$ D. Jeste $\cdot$ I. Grant Department of Psychiatry (8231), University of California, San Diego,

220 Dickinson Street, Suite B,

San Diego, CA 92103-8231, USA

e-mail: spwoods@ucsd.edu

C. Depp · D. Jeste

Sam and Rose Stein Institute for Research on Aging, University of California, San Diego,

La Jolla, CA, USA

\section{S. L. Letendre}

Department of Medicine, University of California, San Diego,

School of Medicine,

La Jolla, CA, USA rates of major depressive disorder and current affective distress (e.g., depression, anxiety). Moreover, the SCA group evidenced better everyday functioning outcomes, including medication adherence, lower self-reported rates of declines in activities of daily living, and superior abilities related to medication management and dealing with healthcare providers. SCA was not related to demographic composition, HIV disease or treatment factors, medical comorbidities, or histories of substance use disorders. Findings from this preliminary study suggest that approximately one-third of older persons with HIV were free of cognitive impairments, which is associated with more favorable emotional, psychosocial, and everyday functioning.

Keywords Neuropsychological assessment · Aging · Treatment adherence AIDS dementia $\cdot$ Depression

\section{SCA in persons living with HIV infection}

The growth of the population aged 60 or over is currently more than twice the growth rate of the total world population $(2.6 \%$ and $1.2 \%$, respectively; Department of Economic and Social Affairs Population Division 2009), and an increasing number of these individuals are infected with human immunodeficiency virus (HIV). The successful introduction of combination antiretroviral therapies (cART) in the mid-1990s has contributed to a significant decline in the mortality associated with HIV and acquired immunodeficiency syndrome (AIDS). More than one-quarter of people living with HIV/AIDS in the USA are now over the age of 50, which represents more than a $60 \%$ increase from 2001 (CDC 2008b). In addition, individuals over the age of 50 account for $15 \%$ of incident cases of HIV (CDC 2008a). 
By the year 2015, it is estimated that more than half of the HIV/AIDS population in the USA will be over 50 years old (Smith 2006). Given the rapid growth of this population, it is becoming increasingly important to understand the risk and protective factors relevant to aging with HIV.

Older individuals face a variety of unique medical risks and challenges pertaining to HIV infection. For example, older HIV-infected adults are at greater risk of more rapid disease progression (e.g., Phillips et al. 1991) and mortality (e.g., CDC 2008b; Egger et al. 2002), likely due to a variety of factors, including delayed diagnosis and medical care (Bamford et al. 2010), immune downregulation (e.g., Gardner 1980), and diminished and delayed immunologic reconstitution with cART. There is also a higher prevalence of comorbidities among older adults with HIV such as hypertension, hypertriglyceridemia, low bone mineral density, frailty, and lipodystrophy (Onen et al. 2010).

The central nervous system (CNS) is also vulnerable to the combined effects of age-related changes and HIV. Older HIVinfected adults may show disproportionate changes in brain structure (e.g., Ernst and Chang 2004; Jernigan et al. 2005) and function (e.g., Larussa et al. 2006; Valcour et al. 2004), although research on this issue is not conclusive (e.g., Scott et al. in press). The prevalence of HIV-associated neurocognitive disorders (HAND), including HIV-associated dementia (HAD), tends to be higher in older adults (Becker et al. 2004; Valcour et al. 2004). For example, Valcour and colleagues (2004) found that, even after controlling for important confounding variables, older HIV-infected persons were three times more likely to be diagnosed with HAD than younger patients. Consistent with the primary effects of HIV on white matter and the frontostriatal circuits, older adults with HIV evidence neurocognitive impairment compared to healthy comparison subjects on measures of executive functions, episodic memory, and information processing speed (e.g., Cherner et al. 2004; Sacktor et al. 2007). In regard to functional implications of such deficits in this population, neurocognitive impairments relate to worse everyday functioning outcomes (e.g., Thames et al. in press), including adherence to antiretrovirals (ARV; Hinkin et al. 2004), among older HIV-infected adults. Possible risk factors for HAND among older adults include advanced HIV disease (e.g., Cherner et al. 2004; Woods et al. 2010), substance abuse (e.g., Becker et al. 2004), and cardiovascular disease (e.g., Becker et al. 2009; Foley et al. 2010).

Despite the convergence of CNS risk factors imposed by aging and HIV, there is considerable heterogeneity in outcomes such that some older HIV-infected adults avoid cognitive morbidity (e.g., Cole et al. 2007). Indeed, while the existing literature is largely focused on a "deficit approach," understanding the characteristics of older individuals with HIV who are "aging successfully" (e.g., free from actual and perceived cognitive impairment) may help to inform preventative efforts. Although there is no single consensus definition of successful aging (see Depp and Jeste 2006 for a review), a number of recent reports have focused on successful cognitive aging (SCA Depp et al. 2010; Fiocco and Yaffe 2010). SCA broadly refers to the multidetermined process of preserving cognitive abilities, or exhibiting lessthan-expected decline in neural structure and function typically associated with aging and its comorbidities. Research, to date, suggests that SCA is associated with higher levels of cognitive and brain reserve (e.g., Stern 2003), which may be due to developing cognitive resources earlier in life (e.g., education) or from neurobehavioral adaptations later in life. Predictors of SCA include psychosocial factors such as resilience to stressors (Lamond et al. 2008), freedom from syndromal or subsyndromal depression (Vahia et al. 2009), social support (Daffner 2010), and healthy lifestyle behaviors (e.g., diet and exercise; Daffner 2010; Yaffe et al. 2009). Importantly, many of the emerging predictive factors of SCA, such as exercise and smoking, can be modified by behavioral change and therefore possibly promote SCA (e.g., AgueroTorres et al. 2001; Tomaszewski Farias et al. 2009).

Little research has been devoted to studying cognitive function in older HIV-infected adults, and to our knowledge, no studies have investigated SCA in this growing subpopulation of the HIV epidemic. Thus, the aim of our study was to determine the prevalence, predictors (i.e., demographic, psychiatric, and medical), and functional outcomes of SCA in a modest sample of older persons living with HIV. Given the separate HIV and SCA literatures reviewed above, it was hypothesized that SCA would be associated with higher cognitive reserve (e.g., education), lower rates of depression, less severe HIV disease, and better psychosocial and everyday functioning outcomes (e.g., medication adherence).

\section{Method}

\section{Participants}

The study sample consisted of 74 individuals selected from a larger National Institute of Mental Health (NIMH)-funded study of HIV and memory (see Woods et al. 2009). Participants were recruited from the general community and local HIV treatment clinics. Inclusion criteria for the current study were: (1) positive HIV serostatus as determined by enzyme-linked immunoabsorbent assays and confirmatory Western blot analyses; (2) $\geq 45$ years of age at the time of evaluation; and (3) estimated duration of HIV infection of $\geq 5$ years. Although the age cutoff of 45 years is younger than that generally used for studies on cognitive aging, it is broadly consistent with previous studies examining aging with HIV infection (e.g., Kissel et al. 2005; Lopardo et al. 2009) and with the demographic 
distribution of HIV cases in the USA (CDC 2008a). Participants who demonstrated severe psychiatric (e.g., schizophrenia), neurological (e.g., seizure disorders, stroke, closed head injuries with loss of consciousness greater than 15 min, non-HAD, CNS neoplasms, or opportunistic infections), or general medical (e.g., advanced liver disease or other organ systems failures) conditions that might impact cognition were excluded from the study. Estimated verbal IQ less than 70 (based on the Wechsler Test of Adult Reading; Psychological Corporation 2001), substance dependence within 6 months of study participation, or a urine toxicology screen-positive for illicit drugs (other than marijuana) on the day of study participation were also a basis for exclusion.

\section{Successful cognitive aging}

Although there is no universally agreed upon approach to operationalizing SCA in clinical populations (Depp and Jeste 2006; Fiocco and Yaffe 2010), we used a modified method from neuroAIDS research (e.g., Antinori et al. 2007) that was adapted for the current research question. This operational definition includes both objective and subjective components, as in previous approaches to delineating successful aging (Montross et al. 2006) and in the determination of functional decline in the widely used research criteria for HAND (Antinori et al. 2007). Specifically, we defined our independent variable, SCA, based on participants' performance on a comprehensive, wellvalidated battery of neurocognitive tests and a self-report questionnaire of cognitive complaints. In brief, to be classified in the SCA group, participants must have demonstrated: (1) within normal limits scores (i.e., clinical domain ratings $<5$, which correspond to $>1$ standard deviation below the normative mean described below) on all seven of the performance-based neurocognitive domains assessed; and (2) within normal limits scores (i.e., $<1$ standard deviation above the normative mean) on the ConfusionBewilderment subscale of the Profile of Mood States (POMS; McNair et al. 1981). In the current study sample, the POMS Confusion-Bewilderment scale correlated significantly with clinical ratings of executive functions (Spearman's $\rho=0.31, p=0.008$ ) and speed of information processing (Spearman's $\rho=0.25, p=0.03$ ) and was significantly associated with impairment on the HIV dementia scale using the Morgan et al. (2008) normative standards $\left(X^{2}=4.2, p=0.04\right)$.

Materials and procedure

After providing written, informed consent, participants completed a comprehensive neuropsychological, psychiatric, and medical research evaluation, which had been approved by the University of California, San Diego (UCSD) Human Research Protection Program.

\section{Neurocognitive assessment}

All participants completed a standardized battery of neurocognitive tests designed in accordance with NIMH recommendations to evaluate the cognitive domains most commonly impaired with HIV infection (Antinori et al. 2007), including motor skills, executive functions, attention/working memory, episodic learning, episodic memory, verbal fluency, and information processing speed. The reader is referred to Woods et al. (2008b) for information regarding the neurocognitive battery and to Woods et al. (2004) for details about the well-validated blinded clinical ratings procedures.

\section{Psychiatric assessment}

The POMS, which was used in our operationalization of SCA, is a 65-item, self-report evaluation of current moods states, was used to assess cognitive complaints and acute affective distress (McNair et al. 1981). The POMS instructs participants to rate various adjectives (e.g., "sluggish") on a five-point Likert-type scale ranging from 0 ("not at all") to 4 ("extremely") based on their mood during the week prior to evaluation. POMS items correspond to six subscales (e.g., confusion-bewilderment) that comprise a total mood score in which higher scores indicate greater distress. Raw scores were converted to demographically adjusted $Z$-scores using published normative standards (Nyenhuis et al. 1999). Each participant also received a structured psychiatric assessment in which the Composite International Diagnostic Interview (CIDI version 2.1; World Health Organization 1998) was used to measure lifetime and current (i.e., within 1 month of evaluation) diagnoses of major depressive disorder (MDD), generalized anxiety disorder (GAD), and substance-related disorders according to Diagnostic and Statistical Manual of Mental Disorders (4th edn.; American Psychiatric Association 1994) standards.

\section{Medical assessment}

All participants underwent a full neuromedical evaluation, which consisted of a thorough assessment of medications, medical history, and current symptoms, a complete physical and neurological evaluation, Centers for Disease Control (CDC) staging, lumbar puncture, and blood draw. Reverse transcriptase-polymerase chain reaction (RT-PCR; Amplicor, Roche Diagnostics, Indianapolis, IN) was used to measure levels of HIV ribonucleic acid (RNA) in plasma and cerebrospinal fluid. 


\section{Psychosocial and functional characteristics}

Activities of daily living Participants' self-reported ability to perform activities of daily living (ADL was measured by a modified version of the Lawton and Brody (1969) ADL scale, which included 13 items assessing current and best prior levels of functioning (e.g., financial and medication management). Participants were classified as ADL dependent if they demonstrated current decline from best to now in two or more categories (see Heaton et al. 2004; Woods et al. 2008a).

Socioeconomic status To assess participant socioeconomic status (SES), the Hollingshead SES scale was used (Hollingshead 1975). The Hollingshead SES scale takes into account marital status, gender, education, and occupation. Employment status (i.e., full-time gainful employment) was assessed by a simple self-report question embedded in the neurobehavioral interview. The overall rate of full-time employment was $36 \%$, which is generally consistent with prior studies in the cART era (e.g., Burns et al. 2006).

Beliefs related to medication adherence (BERMA) The BERMA survey was used to evaluate each participant's medication management (McDonald-Miszczak et al. 2004). Specifically, the BERMA questionnaire assesses three domains of adherence-related beliefs: memory for medications, dealing with health professionals, and attitudes about medications. The survey consists of 53 items, with 20 items dedicated to medication adherence (e.g., "I am less efficient at adhering to my medication regimen than I used to be"), 23 items for assessing participants' relationship with healthcare providers (e.g., "I have difficulty talking openly with my physician"), and ten items addressing attitudes concerning medications (e.g., "I am taking too much medication for my medical conditions"). Participants are instructed to rate each BERMA item on a five-point Likert scale ranging from 1 ("strongly disagree") to 5 ("strongly agree"). Note that several items necessitate reverse scoring such that higher values reflect better medication adherence.

Medication adherence ARV adherence was also directly measured for a subset of the population $(n=37)$ with the medication event monitoring system (MEMS; Aprex, Union City, CA). The MEMS procedure used in this study is described in detail elsewhere (see Woods et al. 2009). In short, participants took their ARV medication for 4 weeks from a pill bottle with a cap (Trackcap ${ }^{\circledR}$ ) containing a microchip device designed to record the time, date, and frequency with which the participants opened their medication bottles. Adherence was recorded as percent of doses taken as prescribed.
Statistical analyses

The study sample $(\mathrm{SCA}=24$, Comparison $=50)$ provided sufficient statistical power $(1-\beta=0.89)$ to detect large univariate and Chi-square between-group effect sizes (Erdfelder et al. 1996). To examine differences between the SCA group and Comparison group, paired $t$-tests (or their nonparametric equivalents [e.g., Wilcoxon rank sums test] for non-normally distributed variables) were used for continuous variables and the Chi-square statistic was used for categorical variables. For continuous variables, we also generated estimates of effect size using the Cohen's $d$ statistic.

\section{Results}

Based on our study criteria, 24 out of the 74 HIV-infected participants (32\%) were classified as exhibiting SCA. The SCA group had a median global clinical neurocognitive rating of 3 (interquartile range $[\mathrm{IQR}]=2,3$ ), whereas the median in the comparison group was 4 (IQR=4, 5.3; $p<0.01$ ). The median POMS confusion/bewilderment Z-scores of the SCA and comparison groups were $-0.63(\mathrm{IQR}=-1.1,-0.2)$ and 0.58 (IQR $=-0.2,1.6)$, respectively $(p<0.01)$. As shown in Table 1, the SCA and comparison groups did not differ significantly in age, sex, or ethnic identity (all $p$ values $>0.10$ ). Similarly, there were no between-groups differences in any of our measures of cognitive reserve, including years of education, WTAR estimated verbal IQ, and the Hollingshead score (all $p$ values $>0.10$ ).

Table 1 also shows that individuals in the SCA group were significantly less likely to have had MDD during their lifetime $(p<0.05)$. The prevalence of lifetime MDD in the SCA group $(33 \%)$ was less than half that which was observed in the comparison sample (70\%). A post hoc logistic regression revealed that lifetime MDD predicted self-report SCA as measured by the POMS $(p=0.03)$, but not performancebased SCA as measured by the clinical ratings of neurocognitive deficits $(p=0.20)$. Individuals in the SCA group did not differ from those in the comparison group in likelihood of current major depressive, lifetime generalized anxiety, or substance dependence disorders (all $p$ values $>0.10$ ). No study participants in either group demonstrated current generalized anxiety disorder. In terms of current affective distress, however, individuals in the SCA group endorsed significantly lower scores on the POMS subscales of tension-anxiety, depression-dejection, anger-hostility, and fatigue-inertia (all $p$ values $<0.05$ ), as well as higher POMS vigor-activation scores $(p<0.05)$.

Contrary to our study hypotheses, the two groups did not differ in any measures of HIV disease severity or treatment including years of HIV infection, AIDS diagnosis, cART status, nadir and current CD4 counts, or HIV RNA in plasma 
Table 1 Demographic and psychiatric characteristics of the study samples
SCA Successful cognitive aging, WTAR Wechsler Test of Adult Reading.

\begin{tabular}{|c|c|c|c|c|}
\hline & $\begin{array}{l}\text { HIV+SCA }(n=24) \\
\text { M(SD) or } \%\end{array}$ & HIV+comparison $(n=50)$ & $p$ Values & Cohen's $d$ \\
\hline \multicolumn{5}{|c|}{ Demographic characteristics } \\
\hline Age (years) & $52.1(6.6)$ & $50.9(5.1)$ & 0.416 & 0.21 \\
\hline Sex (female) & $8.3 \%$ & $12.0 \%$ & 1.000 & \\
\hline Ethnicity (Caucasian) & $62.5 \%$ & $66.0 \%$ & 0.768 & \\
\hline \multicolumn{5}{|l|}{ Cognitive reserve } \\
\hline Education (years) & $13.3(3.1)$ & $13.9(2.3)$ & 0.366 & -0.23 \\
\hline WTAR verbal IQ & $104.5(12.8)$ & $102.9(11.4)$ & 0.610 & 0.13 \\
\hline Hollingshead score & $36.6(13.5)$ & $34.8(13.5)$ & 0.590 & 0.13 \\
\hline \multicolumn{5}{|l|}{ Psychopathology } \\
\hline \multicolumn{5}{|c|}{ Major depressive disorder } \\
\hline Current & $4.2 \%$ & $14.0 \%$ & 0.262 & \\
\hline Lifetime & $33.3 \%$ & $70.0 \%$ & 0.003 & \\
\hline \multicolumn{5}{|l|}{ Generalized anxiety } \\
\hline Current & $0 \%$ & $0 \%$ & $\mathrm{~N} / \mathrm{A}$ & \\
\hline Lifetime & $8.3 \%$ & $4.0 \%$ & 0.591 & \\
\hline Substance dependence & $45.8 \%$ & $58.0 \%$ & 0.326 & \\
\hline \multicolumn{5}{|l|}{ Profile of mood states } \\
\hline Tension/anxiety & $6.2(4.6)$ & $8.8(6.2)$ & 0.046 & -0.45 \\
\hline Depression/dejection & $4.7(5.8)$ & $9.6(10.8)$ & 0.013 & -0.51 \\
\hline Anger/hostility & $3.4(4.0)$ & $6.5(7.0)$ & 0.023 & -0.50 \\
\hline Vigor/activation & $19.4(6.9)$ & $14.3(6.4)$ & 0.004 & 0.77 \\
\hline Fatigue/inertia & $5.4(5.4)$ & $8.8(7.1)$ & 0.030 & -0.51 \\
\hline
\end{tabular}

and cerebrospinal fluid (CSF; all $p$ values $>0.10$ ). There were also no between-group differences observed in any other medical characteristics including hepatitis $\mathrm{C}$ co-infection, hypertension, hypercholesterolemia, or type II diabetes mellitus (all $p$ values $>0.10$ ). These data are displayed in Table 2 .

Finally, we were interested in determining whether SCA was associated with any advantages in daily functioning (see Table 3). Results showed that SCA was significantly associated with better self-reported medication management as measured by the BERMA $(p<0.05)$, as well as better ARV adherence as measured by a 30-day behavioral assessment using MEMS caps $(p<0.05)$. The SCA and comparison groups did not differ in their attitudes about medications $(p>0.10)$. There was no difference between the two groups in employment status $(p>0.10)$, but individuals in the SCA group reported significantly greater comfort in dealing with healthcare professionals and lower rates of ADL dependence ( $p$ values $<0.05)$.
Table 2 HIV disease and medical characteristics of the study samples

cART Combined antiretroviral therapy, $S C A$ successful cognitive aging

\begin{tabular}{lcccc}
\hline & HIV+SCA $(n=24)$ & HIV+comparison $(n=50)$ & $p$ Values & Cohen's $d$ \\
\hline HIV disease characteristics & & & & \\
Duration of infection (years) & $18.5(5.9)$ & $15.9(6.6)$ & 0.177 & 0.40 \\
AIDS (\%) & 79.2 & 68.0 & 0.413 & - \\
cART (\%) & 91.7 & 76 & 0.127 & - \\
Nadir CD4 (cells/ $\mu$ l) & $127.9(112.9)$ & $172.0(203.1)$ & 0.926 & -0.24 \\
Current CD4 (cells/ $\mu$ l) & $502.4(261.8)$ & $544.8(328.6)$ & 0.698 & -0.14 \\
Plasma HIV RNA (\% det.) & 29.2 & 30.0 & 0.941 & - \\
CSF HIV RNA (\% det.) & 15.0 & 19.4 & 0.688 & - \\
Other medical characteristics & & & & \\
Hepatitis C & $21.7 \%$ & $22.9 \%$ & 1.000 & - \\
Hypertension & $16.7 \%$ & $18.0 \%$ & 1.000 & - \\
Hypercholesterolemia & $0 \%$ & $8.0 \%$ & 0.297 & - \\
Diabetes mellitus & $8.3 \%$ & $6.0 \%$ & 0.657 & - \\
\hline
\end{tabular}


Table 3 Psychosocial and functional characteristics of the study samples

\begin{tabular}{|c|c|c|c|c|}
\hline & $\mathrm{HIV}+\mathrm{SCA}(n=24)$ & HIV+comparison $(n=50)$ & $p$ Values & Cohen's $d$ \\
\hline \multicolumn{5}{|l|}{ Berma } \\
\hline Memory for medications & $82.8(11.5)$ & $73.4(12.7)$ & 0.002 & 0.75 \\
\hline Dealing with health professionals & $99.2(13.2)$ & $91.3(14.1)$ & 0.022 & 0.57 \\
\hline Attitudes about medications & $37.3(6.9)$ & $35.5(5.9)$ & 0.272 & 0.29 \\
\hline ADL dependence (\%) & $12.5 \%$ & $40.8 \%$ & 0.017 & - \\
\hline Unemployed (\%) & $65 \%$ & $67 \%$ & 0.851 & - \\
\hline MEMS ART adherence ${ }^{\mathrm{a}}$ & $97.5(6.2)$ & $89.9(17.2)$ & 0.036 & 0.55 \\
\hline
\end{tabular}

ART Antiretroviral therapy, BERMA beliefs related to medication adherence, MEMS medication event monitoring system, $S C A$ successful cognitive aging

${ }^{a}=16$ for HIV+SCA and $n=21$ for HIV+comparison group

\section{Discussion}

To our knowledge, this is the first study to examine the prevalence, correlates, and everyday functioning outcomes of SCA in older adults living with HIV infection, who are a growing subpopulation of the HIV epidemic that is at risk for considerable medical and psychological morbidity, including HAND. We observed a $32 \%$ prevalence of SCA in this HIV+ cohort, which was defined as the absence of neurocognitive impairment across seven functional domains as measured by both performance-based tests and selfreport of cognitive difficulties in daily life. These data indicate that approximately one-third of older adults with HIV are able to evade even mild forms of neuropsychological impairment. Findings converge with those of Cole and colleagues (2007), who reported that psychomotor skills were preserved in long-term, asymptomatic HIV+ survivors. It is notable that the rate of freedom from cognitive impairment in this study was similar to that seen in samples of older adults with a much older mean age (Montross et al. 2006; Yaffe et al. 2010). Thus, while a minority of patients with HIV are able to retain cognitive functions across a wide variety of domains in rates similar to seronegatives, these data raise questions about whether prevalence rates of SCA in HIV will decline as the population ages.

Contrary to our study hypotheses, results revealed no associations between SCA and cognitive reserve or HIV disease severity. Cognitive reserve has been linked to SCA in healthy populations (Yaffe et al. 2009) and also has been shown to negatively predict neuropsychological performance in younger HIV populations (e.g., Basso and Bornstein 2000; Stern et al. 1996). That cognitive reserve did not predict SCA in our older HIV+ cohort was thus unexpected, and may reflect the limitations of our relatively small samples, cross-sectional study design, and use of both self-report and performance-based neurocognitive indicators of SCA. Inclusion of biological measures of brain reserve (e.g., morphometry or diffusion tensor imaging) might be also be more sensitive to SCA in older HIVinfected populations (e.g., Sumowski et al. 2009). Relatedly, it was surprising that none of the HIV disease severity or treatment characteristics we measured were predictive of SCA. It is possible that the relative immune health of our sample (e.g., median current $\mathrm{CD} 4>500$ cells $/ \mu$ l) may have precluded detection of differences between the two groups. It is also possible that the current clinical HIV disease variables reported herein are not as strongly associated with cognitive functioning in the cART era (e.g., Sevigny et al. 2004). As such, prospective studies informed by current models of the neuropathogenesis of HAND might examine such neuroprotective factors as brain-derived neurotrophic factor, fibroblast growth factors, and erythropoietin might be considered (e.g., Mocchetti et al. 2008).

Shifting our focus now to the psychiatric correlates of SCA, HIV+ individuals with SCA were significantly less likely to meet lifetime diagnostic criteria for MDD and endorsed an overall lower severity of current affective distress, including depression and anxiety during their lives, which is in agreement with much of the general SCA literature. The prevalence of lifetime MDD in the SCA group (33\%) was less than half that which was observed in the comparison sample $(70 \%)$. Studies of healthy, highfunctioning older individuals reliably implicate depression as a risk factor for cognitive decline (e.g., Chodosh et al. 2007; Yaffe et al. 2009). Within the neuroAIDS literature, depression is strongly related to elevated cognitive complaints (e.g., Rourke et al. 1999); however, it is not typically associated with the prevalence or incidence of HAND (e.g., Cysique et al. 2007), regardless of the etiology of MDD (e.g., primary). For example, Cysique and colleagues (2007) found that neither lifetime nor incident MDD was associated with performance on a comprehensive battery of cognitive tests in an HIV+ sample. However, these were younger adults, perhaps it takes time for the effects of depression to alter cognitive trajectories. Interestingly, a post hoc analysis within the 
current study sample provided further support for this notion by revealing that lifetime MDD predicted self-report SCA, but not performance-based SCA. Thus, our results converge with the existing literature on depression and HAND by suggesting that individuals without histories of depression are less likely to report having experienced neurocognitive declines.

Although the rates of current MDD did not differ between groups, the SCA group reported higher levels of vigor and lower levels of anxiety, dejection, anger, and fatigue than the comparison group. These results suggest that acute affective distress is negatively associated with SCA, likely as a function of its correspondence with neurocognitive complaints. One possible interpretation of this finding is that the SCA group was better able to avoid the negative effects of stress on perceived cognitive problems, perhaps by way of resilience. Still, it should be noted that we used participants' scores on one POMS subscale (i.e., confusion/bewilderment) to classify participants into the SCA group. Although there is no direct item overlap between this POMS subscale and other POMS subscales (and thus no true criterion contamination), it may be expected that responses in one POMS domain will correlate strongly with responses in the other five domains. Indeed, the average interscale intercorrelation in this sample was 0.60 (range $=-0.45$ to 0.70 ). Future studies of SCA in HIV-infected populations would benefit from inclusion of more independent measures of cognitive complaints (e.g., Patient's Assessment of Own Functioning Inventory; Rourke et al. 1999). Additionally, it may be useful to investigate other aspects of mood and affect, such as apathy, in the context of SCA in HIV infection (Hoare et al. 2010; Paul et al. 2005).

The most consistent finding from this study was that SCA was associated with a variety of beneficial everyday functioning outcomes. These findings extend the literature on HIV-associated neurocognitive impairment and everyday functioning by focusing on SCA (see Marcotte and Grant 2010). Individuals in the SCA group were nearly fivefold less likely to report ADL dependence than persons in the comparison group. SCA was also associated with superior medication management abilities, as measured by generic self-report (i.e., BERMA) and a behavioral index of cART adherence (i.e., MEMS). These findings were associated with medium effect sizes and are consistent with prior literature suggesting that $\mathrm{HIV}$-associated neurocognitive impairment, especially in the domains of executive functions and episodic memory, increases the likelihood of nonadherence (e.g., Hinkin et al. 2002). Although in general, older age has been associated with better medication adherence among HIV-infected individuals (e.g., Ettenhofer et al. 2009), it also has been shown that neurocognitive impairment increases the risk of poor medication adherence in older HIV patients (Hinkin et al. 2004). The directionality of the relationship, however, is unclear since it is not only possible that SCA allows HIV-infected individuals to maintain their functional independence, but also that those HIV patients who continue to perform ADLs, in particular adherence, may be more likely to achieve successful cognitive outcomes (e.g., Ettenhofer et al. 2010). Regardless, maintaining independence in functional activities is an important goal for a chronic medical condition, such as HIV, as functional dependence has been shown to predict mortality (e.g., Shen et al. 2005). Thus, understanding the factors that contribute to independence in ADLs is crucial and should be a focus of medical and psychological intervention development, including strategies that might promote SCA (e.g., cognitive enrichment).

We also found that HIV+ individuals with SCA were more likely to report better interactions with their healthcare providers. Older HIV patients must interact with wide range of healthcare professionals on a regular basis, and our results support the importance of constructive interactions between these caregivers and their older HIV-infected patients. There are several potential explanations of our findings. First, it is possible that those who are less impaired are able to communicate more effectively with their healthcare providers. Further, it is also possible that those older HIV patients who are more comfortable interacting with their healthcare professionals are more likely to achieve successful cognitive outcomes because these patients are more likely to openly discuss their health needs and concerns with their healthcare providers (although patterns of treatment were not different between groups). Finally, older HIV patients may be more likely to adhere to the instructions of healthcare providers in whom they are most confident, resulting in better cognitive outcomes in these patients. Given this range of possibilities, future research should more closely examine the connection between cognitive outcomes and older HIV patients' dealings with their healthcare providers. Such work may elucidate aspects of relationships between healthcare providers and older HIV patients essential for promoting SCA. If such factors are determined, healthcare providers could potentially promote SCA in their older HIV-infected patients simply by altering the way in which they interact with these patients.

The results of this study should be interpreted in light of the following limitations. First, the study sample size was relatively small and thereby only allowed us to detect medium-to-large effects. Second, the study used a crosssectional design, which did not permit the examination of directionality of causal effects. Ideally, future HIV infection would involve following neurocognitively normal, but at-risk older individuals prior to seroconversion and throughout the course of their infection. Third, our study did not include other relevant predictors of SCA including psychosocial variables, such as resilience (Lamond et al. 2008), spirituality (Vahia et 
al. in press) and wisdom (Blazer 2006), and health behaviors, such as exercise and smoking (e.g., Yaffe et al. 2009). Thus, it will be important to confirm and extend the results reported here using a prospective, longitudinal study design that includes larger samples of HIV-infected (and demographically comparable seronegative) older adults. Such studies will help to identify important risk and protective factors in regard to trajectories of cognitive aging, which may facilitate the development of effective interventions aimed at promoting SCA and better quality of life among persons living with HIV infection.

Acknowledgments The HIV Neurobehavioral Research Center (HNRC) Group is affiliated with the University of California, San Diego, the Naval Hospital, San Diego, and the Veterans Affairs San Diego Healthcare System. The group includes: Director: Igor Grant, M.D.; CoDirectors: J. Hampton Atkinson, M.D., Ronald J. Ellis, M.D., Ph.D., and J. Allen McCutchan, M.D.; Center Manager: Thomas D. Marcotte, Ph. D.; Naval Hospital San Diego: Braden R. Hale, M.D., M.P.H. (P.I.); Neuromedical Component: Ronald J. Ellis, M.D., Ph.D. (P.I.), J. Allen McCutchan, M.D., Scott Letendre, M.D., Edmund Capparelli, Pharm. D., Rachel Schrier, Ph.D.; Neurobehavioral Component: Robert K. Heaton, Ph.D. (P.I.), Mariana Cherner, Ph.D., David J. Moore, Ph.D., Steven Paul Woods, Psy.D.; Neuroimaging Component: Terry Jernigan, Ph.D. (P.I.), Christine Fennema-Notestine, Ph.D., Sarah L., Archibald, M.A., John Hesselink, M.D., Jacopo Annese, Ph.D., Michael J. Taylor, Ph.D.; Neurobiology Component: Eliezer Masliah, M.D. (P.I.), Ian Everall, FRCPsych., FRCPath., Ph.D., T. Dianne Langford, Ph.D.; Neurovirology Component: Douglas Richman, M.D., (P.I.), David M. Smith, M.D.; International Component: J. Allen McCutchan, M.D., (P. I.); Developmental Component: Ian Everall, FRCPsych., FRCPath., Ph. D. (P.I.), Stuart Lipton, M.D., Ph.D.; Clinical Trials Component: J. Allen McCutchan, M.D., J. Hampton Atkinson, M.D., Ronald J. Ellis, M.D., Ph.D., Scott Letendre, M.D.; Participant Accrual and Retention Unit: J. Hampton Atkinson, M.D. (P.I.), Rodney von Jaeger, M.P.H.; Data Management Unit: Anthony C. Gamst, Ph.D. (P.I.), Clint Cushman, B.A., (Data Systems Manager), Daniel R. Masys, M.D. (Senior Consultant); Statistics Unit: Ian Abramson, Ph.D. (P.I.), Christopher Ake, Ph.D., Florin Vaida Ph.D.

This research was supported, in part, by National Institute of Health grants R01-MH073419 (Dr. Woods), P30-MH62512 (Dr. Grant), T35AG026757 (Dr. Jeste), and by the Sam and Rose Stein Institute for Research on Aging. The views expressed in this article are those of the authors and do not reflect the official policy or position of the Department of the Navy, Department of Defense, nor the United States Government.

Open Access This article is distributed under the terms of the Creative Commons Attribution Noncommercial License which permits any noncommercial use, distribution, and reproduction in any medium, provided the original author(s) and source are credited.

\section{References}

Aguero-Torres H, von Strauss E, Viitanen M, Winblad B, Fratiglioni L (2001) Institutionalization in the elderly: the role of chronic diseases and dementia. cross-sectional and longitudinal data from a population-based study. J Clin Epidemiol 54(8):795-801

American Psychiatric Association (1994) Diagnostic and statistical manual of mental disorders, 4th edn. American Psychiatric Association, Washington, DC
Antinori A, Arendt G, Becker JT, Brew BJ, Byrd DA, Cherner M et al (2007) Updated research nosology for HIV-associated neurocognitive disorders. Neurology 69(18):1789-1799

Bamford LP, Ehrenkranz PD, Eberhart MG, Shpaner M, Brady KA (2010) Factors associated with delayed entry into primary HIV medical care after HIV diagnosis. AIDS 24(6):928-930

Basso MR, Bornstein RA (2000) Estimated premorbid intelligence mediates neurobehavioral change in individuals infected with HIV across 12 months. J Clin Exp Neuropsychol 22:208-218

Becker JT, Lopez OL, Dew MA, Aizenstein HJ (2004) Prevalence of cognitive disorders differs as a function of age in HIV virus infection. AIDS 18(Suppl 1):S11-S18

Becker JT, Kingsley L, Mullen J, Cohen B, Martin E, Miller EN et al (2009) Vascular risk factors, HIV serostatus, and cognitive dysfunction in gay and bisexual men. Neurology 73(16):1292-1299

Blazer DG (2006) Successful aging. Am J Geriatr Psychiatry 14(1):2-5

Burns SM, Young LRL, Maniss S (2006) Predictors of employment and disability among people living with HIV/AIDS. Rehabil Psychol 51(2):127-134

Centers for Disease Control and Prevention (2008a) HIV surveillance report. Centers for Disease Control and Prevention, Atlanta

Centers for Disease Control and Prevention (2008b) HIV/AIDS among persons aged 50 and older. Centers for Disease Control and Prevention, Atlanta

Cherner M, Ellis RJ, Lazzaretto D, Young C, Mindt MR, Atkinson JH et al (2004) Effects of HIV-1 infection and aging on neurobehavioral functioning: preliminary findings. AIDS 18(Suppl 1):S27-S34

Chodosh J, Kado DM, Seeman TE, Karlamangla AS (2007) Depressive symptoms as a predictor of cognitive decline: MacArthur studies of successful aging. Am J Geriatr Psychiatry 15(5):406-415

Cole MA, Margolick JB, Cox C, Li X, Selnes OA, Martin EM et al (2007) Longitudinally preserved psychomotor performance in long-term asymptomatic HIV-infected individuals. Neurology 69 (24):2213-2220

Cysique LA, Deutsch R, Atkinson JH, Young C, Marcotte TD, Dawson $L$ et al (2007) Incident major depression does not affect neuropsychological functioning in HIV-infected men. J Int Neuropsychol Soc 13(1):1-11

Daffner KR (2010) Promoting successful cognitive aging: a comprehensive review. J Alzheimers Dis 19(4):1101-1122

Department of Economic and Social Affairs Population Division (2009) World population ageing 2009. United Nations, New York

Depp CA, Jeste DV (2006) Definitions and predictors of successful aging: a comprehensive review of larger quantitative studies. Am J Geriatr Psychiatry 14(1):6-20

Depp C, Vahia I, Jeste DV (2010) Successful aging: focus on cognitive and emotional health. Annu Rev Clin Psychol 6:527-550

Egger M, May M, Chene G, Phillips AN, Ledergerber B, Dabis F et al (2002) Prognosis of HIV-1-infected patients starting highly active antiretroviral therapy: a collaborative analysis of prospective studies. Lancet 360(9327):119-129

Erdfelder E, Faul F, Buchner A (1996) GPOWER: a general power analysis program. Behav Res Meth Instrum Comput 28:1-11

Ernst T, Chang L (2004) Effect of aging on brain metabolism in antiretroviral-naive HIV patients. AIDS 18(Suppl 1):S61-S67

Ettenhofer ML, Hinkin CH, Castellon SA, Durvasula R, Ullman J, Lam $M$ et al (2009) Aging, neurocognition, and medication adherence in HIV infection. Am J Geriatr Psychiatry 17(4):281-290

Ettenhofer ML, Foley J, Castellon SA, Hinkin CH (2010) Reciprocal prediction of medication adherence and neurocognition in HIV/ AIDS. Neurology 74(15):1217-1222

Fiocco AJ, Yaffe K (2010) Defining successful aging: the importance of including cognitive function over time. Arch Neurol 67 (7):876-880

Foley J, Ettenhofer M, Wright MJ, Siddiqi I, Choi M, Thames AD et al (2010) Neurocognitive functioning in HIV-1 infection: effects 
of cerebrovascular risk factors and age. Clin Neuropsychol 24 (2):265-285

Gardner ID (1980) The effect of aging on susceptibility to infection. Rev Infect Dis 2(5):801-810

Heaton RK, Marcotte TD, Mindt MR, Sadek J, Moore DJ, Bentley H et al (2004) The impact of HIV-associated neuropsychological impairment on everyday functioning. J Int Neuropsychol Soc 10 (3):317-331

Hinkin CH, Castellon SA, Durvasula RS, Hardy DJ, Lam MN, Mason KI et al (2002) Medication adherence among HIV+adults: effects of cognitive dysfunction and regimen complexity. Neurology 59:1944-1950

Hinkin CH, Hardy DJ, Mason KI, Castellon SA, Durvasula RS, Lam MN, Stefaniak M (2004) Medication adherence in HIV-infected adults: effect of patient age, cognitive status, and substance abuse. AIDS 18(Suppl 1):S19-S25

Hoare J, Fouche JP, Spottiswoode B, Joska JA, Schoeman R, Stein DJ, Carey PD (2010) White matter correlates of apathy in HIV-positive subjects: a diffusion tensor imaging study. J Neuropsychiatry Clin Neurosci 22(3):313-320

Hollingshead AB (1975) Four-factor index of social status. Unpublished manuscript. Yale University, New Haven

Jernigan TL, Gamst AC, Archibald SL, Fennema-Notestine C, Rivera Mindt M, Marcotte TD et al (2005) Effects of methamphetamine dependence and HIV infection on cerebral morphology. Am J Psychiatry 162:1461-1472

Kissel EC, Pukay-Martin ND, Bornstein RA (2005) The relationship between age and cognitive function in HIV-infected men. J Neuropsychiatry Clin Neurosci 17(2):180-184

Lamond A, Depp CA, Reichstadt J, Moore DJ, Golshan S, Jeste DV (2008) Measurement and predictors of resilience in older adults. J Psychiatr Res 43:148-154

Larussa D, Lorenzini P, Cingolani A, Bossolasco S, Grisetti S, Bonglovanni $\mathrm{M}$ et al (2006) HAART reduces the age-associated risk of dementia in a cohort of older HIV-1-infected patients. AIDS Res Hum Retroviruses 22:386-392

Lawton MP, Brody EM (1969) Assessment of older people: selfmaintaining and instrumental activities of daily living. Gerontologist 9(3):179-186

Lopardo GD, Bissio E, Iannella Mdel C, Crespo AD, Garone DB, Cassetti LI (2009) Good neurocognitive performance measured by the international HIV dementia scale in early HIV-1 infection. J Acquir Immune Defic Syndr 1999 52(4):488-492

Marcotte TD, Grant I (2010) Neuropsychology of everyday functioning. The Guilford Press

McDonald-Miszczak L, Maris P, Fitzgibbon T, Ritchie G (2004) A pilot study examining older adults' beliefs related to medication adherence: the BERMA survey. J Aging Health 16(5):591-614

McNair DM, Lorr M, Droppleman LF (1981) Manual for the profile of mood states. Educational and Industrial Testing Service, San Diego

Mocchetti I, Bachis A, Masliah E (2008) Chemokine receptors and neurotrophic factors: potential therapy against aids dementia? J Neurosci Res 86(2):243-255

Montross LP, Depp CA, Daly J, Golshan S, Moore DJ, Sitzer DI, Jeste DV (2006) Defining successful aging: comparing self-ratings with different sets of criteria. Am J Geriatr Psychiatry 14:43-51

Morgan EE, Woods SP, Scott JC, Childers M, Marquie-Beck J, Ellis RJ, Grant I, Heaton RK, The HNRC Group (2008) Predictive validity of demographically-adjusted normative standards for the HIV Dementia Scale. J Clin Exp Neuropsychol 30:83-90

Nyenhuis DL, Yamamoto C, Luchetta T, Terrien A, Parmentier A (1999) Adult and geriatric normative data and validation of the profile of mood states. J Clin Psychol 55(1):79-86

Onen NF, Overton ET, Seyfried W, Stumm ER, Snell M, Mondy K, Tebas P (2010) Aging and HIV infection: a comparison between older HIV-infected persons and the general population. HIV Clin Trials 11(2):100-109

Paul R, Flanigan TP, Tashima K, Cohen R, Lawrence J, Alt E et al (2005) Apathy correlates with cognitive function but not CD4 status in patients with human immunodeficiency virus. J Neuropsychiatry Clin Neurosci 17(1):114-118

Phillips AN, Lee CA, Elford J, Webster A, Janossy G, Timms A, Bofill M, Kernoff PB (1991) More rapid progression to AIDS in older HIV-infected people: the role of CD4+ T-cell counts. J Acquir Immune Defic Syndr 4(10):970-975

Psychological Corporation (2001) Wechsler test of adult reading. Psychological Corporation, San Antonio

Rourke SB, Halman MH, Bassel C (1999) Neurocognitive complaints in HIV-infection and their relationship to depressive symptoms and neuropsychological functioning. J Clin Exp Neuropsychol 21 (6):737-756

Sacktor N, Skolasky R, Selnes OA et al (2007) Neuropsychological test profile differences between young and old human immunodeficiency virus-positive individuals. J Neurovirol 13 (3):203-209

Scott JC, Woods SP, Weber E, Carey CL, Dawson M, Bondi M, Grant I, The HNRC Group (in press) Neurocognitive consequences of HIV infection in older adults: an evaluation of the "cortical" hypothesis. AIDS Behav

Sevigny JJ, Albert SM, McDermott MP, McArthur JC, Sacktor N, Conant K et al (2004) Evaluation of HIV RNA and markers of immune activation as predictors of HIV-associated dementia. Neurology 63(11):2084-2090

Shen JM, Blank A, Selwyn PA (2005) Predictors of mortality for patients with advanced disease in an HIV palliative care program. J Acquir Immune Defic Syndr 40(4):445-447

Smith G (2006) Aging hearing: HIV over fifty, exploring the new threat. Senate Committee on Aging, Washington, DC

Stern Y (2003) The concept of cognitive reserve: a catalyst for research. J Clin Exp Neuropsychol 25(5):589-593

Stern RA, Silva SG, Chaisson N, Evans DL (1996) Influence of cognitive reserve on neuropsychological functioning in asymptomatic human immunodeficiency virus-1 infection. Arch Neurol 53(2): $148-153$

Sumowski JF, Chiaravalloti N, DeLuca J (2009) Cognitive reserve protects against cognitive dysfunction in multiple sclerosis. J Clin Exp Neuropsychol 31(8):913-926

Thames AD, Kim MS, Becker BW, Foley JM, Hines LJ, Singer EJ et al (in press) Medication and finance management among HIVinfected adults: the impact of age and cogntion. J Clin Exp Neuropsychol

Tomaszewski Farias S, Cahn-Weiner DA, Harvey DJ, Reed BR, Mungas D, Kramer JH, Chui H (2009) Longitudinal changes in memory and executive functioning are associated with longitudinal change in instrumental activities of daily living in older adults. Clin Neuropsychol 23(3):446-461

Valcour V, Shikuma C, Shiramizu B, Watters M, Poff P, Selnes O, Holck P, Grove J, Sacktor N (2004) Higher frequency of dementia in older HIV-1 individuals: the Hawaii aging with HIV-1 cohort. Neurology 63(5):822-827

Vahia IV, Meeks TW, Thompson WK, Depp CA, Zissok S, Allison M et al (2009) Subthreshold depression and successful aging in older women. Am J Geriatr Psychiatry 8:212-220

Vahia I, Depp C, Palmer B, Fellows I, Golshan S, Thompson W, Allison M, Jeste D (in press) Correlates of spirituality in older women. Aging Ment Health

Woods SP, Rippeth JD, Frol AB, Levy JK, Ryan E, Soukup VM et al (2004) Interrater reliability of clinical ratings and neurocognitive diagnoses in HIV. J Clin Exp Neuropsychol 26(6):759-778

Woods SP, Iudicello JE, Moran LM, Carey CL, Dawson MS, Grant I et al (2008a) HIV-associated prospective memory impairment increases 
risk of dependence in everyday functioning. Neuropsychology 22:110-117

Woods SP, Moran LM, Carey CL, Dawson MS, Iudicello JE, Gibson $S$ et al (2008b) Prospective memory in HIV infection: Is "remembering to remember" a unique predictor of self-reported medication management? Arch Clin Neuropsychol 23:257-270

Woods SP, Dawson MS, Weber E, Gibson S, Grant I, Atkinson JH, HNRC Group (2009) Timing is everything: antiretroviral nonadherence is associated with impairment in time-based prospective memory. J Int Neuropsychol Soc 15(1):42-52

Woods SP, Dawson MD, Weber E, Grant I, The HNRC Group (2010) The semantic relatedness of cue-intention pairings influences event-based prospective memory failures in older adults with HIV infection. J Clin Exp Neuropsychol 32:398-407

World Health Organization (1998) Composite international diagnostic interview (CIDI, version 2.1). World Health Organization, Geneva

Yaffe K, Fiocco AJ, Lindquist K, Vittinghoff E, Simonsick EM, Newman AB et al (2009) Predictors of maintaining cognitive function in older adults: the health ABC study. Neurology 72 (23):2029-2035

Yaffe K, Lindquist K, Vittinghoff E, Barnes D, Simonsick EM, Newman A et al (2010) The effect of maintaining cognition on risk of disability and death. J Am Geriatr Soc 58(5):889-894 